\title{
THE
}

2019

\section{Social Learning and Communication with Threshold Uncertainty}

Todd Guilfoos

University of Rhode Island, guilfoos@uri.edu

Haoran Miao

Simona Trandafir

University of Rhode Island, mtrandafir@uri.edu

Emi Uchida

University of Rhode Island, euchida@uri.edu

Follow this and additional works at: https://digitalcommons.uri.edu/enre_facpubs

The University of Rhode Island Faculty have made this article openly available.

Please let us know how Open Access to this research benefits you.

This is a pre-publication author manuscript of the final, published article.

Terms of Use

This article is made available under the terms and conditions applicable towards Open Access Policy Articles, as set forth in our Terms of Use.

\section{Citation/Publisher Attribution}

Guilfoos, T., Miao, H., Trandafir, S., \& Uchida, E. (2019). Social learning and communication with threshold uncertainty. Resource and Energy Economics, 55(C), 81-101. doi: 10.1016/j.reseneeco.2018.11.003

Available at: http://dx.doi.org/10.1016/j.reseneeco.2018.11.003

This Article is brought to you for free and open access by the Environmental and Natural Resource Economics at DigitalCommons@URI. It has been accepted for inclusion in Environmental and Natural Resource Economics Faculty Publications by an authorized administrator of DigitalCommons@URI. For more information, please contact digitalcommons-group@uri.edu. 


\title{
Social Learning and Communication with Threshold Uncertainty ${ }^{*}$
}

\begin{abstract}
Using a threshold public bad game, we perform an experiment to test the effects of communication on coordination failure with various levels of threshold uncertainty. We apply two communication treatments to the coordination game: cheap talk between group members (unrestricted) and anonymous written communication from one generation of subjects to another (restricted). We find that the probability of groups coordinating and reaching the socially preferred equilibrium increases significantly with cheap talk and increases moderately with written communication. Repeated communication through cheap talk leads to a higher probability of achieving a set of payoff-dominant equilibria even in the face of threshold uncertainty.
\end{abstract}

Keywords: Threshold uncertainty, Coordination games, Communication, Equilibrium selection, Social learning

JEL: C72 · C90 - D80

\section{Introduction}

Communication is a critical aspect of human interaction and constitutes a core component of most economic transactions. Communication can be seen as an extension of existing institutions used by society to overcome social dilemmas or coordination problems and may lead to socially preferred outcomes (Ostrom and Walker, 1991). Our study aims to understand the effects of different forms of communication on decision makers faced with environmental uncertainty in a coordination game. Uncertainty in a game theoretic sense can be divided into two categories:

7 strategic uncertainty and environmental uncertainty. Strategic uncertainty (sometimes denoted social uncertainty) refers to the uncertainty about group members' actions or future actions.

\footnotetext{
* We thank Andreas Duus Pape and Chris Anderson for helpful comments and Tung Dang for research assistance. This study is based upon work supported in part by the National Science Foundation EPSCoR Track-2 Cooperative Agreement \#IIA-1330406, Collaborative Research: North East Water Resources Network.
} 
Environmental uncertainty refers to uncertain aspects of the game faced by individuals (Messick et al., 1988) ${ }^{1}$. Specifically, the type of environmental uncertainty we are interested in is "threshold uncertainty", in which the level of the threshold required to achieve provision of the public good,

4 or avoid the public bad, is unknown. An example of threshold uncertainty, motivated by climate

5 change, is lack of certainty about the amount of greenhouse gas emissions reductionmitigation

6 necessary to avoid large-scale damage to society, such as "shifting seas" (Rahmstorf, 1999) and

7 glacier retreats (e.g., (Hasenrath and Kruss, 1992) from rising temperatures and weather volatility.

8 When the science is uncertain about the exact threshold at which such damage is avoided, there may remain a calculable probability of damage even if a specific target is met (Kriegler et al., 2009). We test if and how the negative effects of threshold uncertainty can be mitigated by eommunication-by resolving coordination problems and learning about successful strategies to avoid damages through two types of communication.

Threshold uncertainty presents itself in different ways depending on the game being played. Two important classes of coordination games in environmental economics that have threshold uncertainty are threshold public good games and moral hazard games whereen group fines are used to induce socially optimal outcomes, such as the one described by Segerson (1988) to deal with ambient pollution. ${ }^{2}$ Moral hazard games intersect the coordination game literature, specifically ambient pollution games. Ambient pollution games involve groups of individuals that produce pollution, which is then measured at the ambient (group) level because pollution can only be attributed to the group and not to any specific individual. When considering a group fine based on the ambient level of pollution, which aligns individual incentives with the optimal ambient pollution behavior, this game is the same as a threshold public bad game. A public good game in which penalties or damages are incurred when investment in the public good fails to meet a target (or threshold) is a type of coordination game that is similar in nature to the stag hunt game. Another kind of coordination game is the discrete public good game, also called a subscription game. ${ }^{3}$

\footnotetext{
${ }^{1}$ We do not mean to imply that uncertainty is the same as ambiguity about the game being played, but rather uncertainty refers to a known distribution that creates a stochastic state space in a game.

${ }^{2}$ The ambient pollution with tax-subsidy mechanism described by Segerson (1988) are not classifications of coordination games. I fact, because of the poor performance of the group fine in experiments it has been given less attention in the literature. Here we are not interested in the performance of the group fine, but rather how behavior in a public bad game with threshold uncertainty varies with different sources of uncertainty.

${ }^{3}$ In a subscription game, the public good is provided only if total contributions meet or exceed a threshold; otherwise, the contributions are returned to the agents.
} 
public good game (Lenton, 2013). These games are used to represent collective action problems in environmental and natural resource management, such as economic dilemmas associated with climate change, ambient pollution, ${ }^{4}$ management of natural resources involving open access where extinction is possible, and private provisioning of public goods (Barbieri and Malueg, 2010). When there are environmental thresholds, coordination is required to achieve the payoff-dominant equilibrium and avoid damages, and infliction of damage often leads to strategies that converge to the less-preferred equilibrium. These games are important because theory does not tell us which equilibrium will be chosen, and uncoordinated decisions may have serious consequences for social welfare. Our experiment draws on the ambient group fine mechanism literature and previous experiments (Spraggon, 2002; Vossler et al., 2006; Suter et al., 2010) by using the basic structure of these games which are a type of threshold public bad games.

Experiments show that communication is beneficial in coordination games (Cooper et al., 1992; Russell et al., 1992; Crawford, 1998; Charness and Grosskopf, 2004; Duffy and Feltovich, 2006; Blume and Ortmann, 2007; Devetag and Ortmann, 2007; Ellingsen and Östling, 2010; Li et al., 2012). They,-typically finding that two-way communication and cheap talk tend to improve efficiency and often lead to the payoff-dominant equilibrium in Pareto-ranked equilibria games. Two-way communication is when subjects can be involved in a back-and-forth dialogue with each other, while cheap talk refers to pre-play communication in which the communication is nonbinding and therefore is 'cheap'. One-way communication can be effective at improving efficiency when symmetry breaking is needed to reach a preferred equilibrium, while two-way communication tends to be effective when repeated and when symmetry breaking is not necessary (Crawford, 1998). One-way communication is restrictive in that it does not allow a dialogue between subjects, but rather one subject sends messages to another subject in the experiment. Roth (1981) finds that cheap talk in games leads subjects to focus on a few fairness norms in coordination games. Cooper et al. (1992) find two-way communication leads to a Pareto dominant equilibrium in games with a less 'risky' strategy choice, while one-way communication does not lead to the Pareto dominant equilibrium. Cason et al. (2012) find that two-way intra-group

\footnotetext{
${ }^{4}$ For instance, when a fine levied against all members of the group is used to correct ambient pollution (Segerson 1988), the abatement mechanism can be characterized as a coordination game. It is composed of multiple equilibriaequilibria meeting the pollution target or not meeting the pollution target-and many of them (meeting the target) include a set of asymmetric equilibria and one symmetric, the socially preferred, equilibrium that the group fine is meant to induce. Interestingly, group-fine mechanisms often do not induce the socially preferred equilibrium and are less effective than other mechanisms for reducing ambient pollution such as taxes.
} 
communication can damage efficiency in a weakest-link contest. Much of the previous work on coordination games focuses on understanding strategic uncertainty when coordination fails (Van Huyck et al., 1990). However, there are other important sources of uncertainty, such as threshold uncertainty.

Threshold public good games (ex. Barrett and Dannenberg, 2014; Suleiman et al., 2001; Croson and Marks, 2000) and similar common pool resource games have been rigorously explored in the lab (Gustafsson et al., 2000; Budescu et al., 1990; Budescu et al., 1995a; Budescu et al., 1995b; Gustafsson et al., 1999a, Gustafsson et al., 1999b; Rapoport et al., 1992; Rapoport et al., 1993; Suleiman et al., 1996; Bochet et al. 2017). Most previous experiments involving coordination games did not investigate how communication could resolve threshold uncertainty, with some exceptions discussed below. Several studies find that threshold uncertainty in public good games decreases contributions significantly (e.g., Levati et al. 2009, Levati et al. 2007). Barrett and Dannenberg (2012) study threshold uncertainty in a coordination game in which an increase in threshold uncertainty changes the nature of the game to a prisoner's dilemma, leading to a significant decrease in collective action to avoid the damage. Barrett and Dannenberg (2014) find that coordination failure is sensitive to threshold uncertainty. Wit and Wilke (1998) research social and environmental uncertainty in a public good game and find that environmental uncertainty only matters when high social uncertainty exists. McBride $(2006,2010)$ show that threshold uncertainty could be disruptive to coordination in a discrete public good game depending on the subject's belief about how important their contribution is to reach the unknown threshold. Bochet et al. (2017) develop a model with threshold uncertainty in a shared resource where various levels of risk of resource collapse exist. The authors demonstrate a 'cautious equilibrium' which would guarantee the existence of the common resource and a 'dangerous equilibrium' which risks a collapse of the resource and find experimental evidence that subjects choose the 'dangerous equilibrium', though they do not test the effects of communication on these equilibria choices. Dannenberg et al. (2014) demonstrate that environmental uncertainty can be disruptive to contributions toward a public good, particularly when the probability distribution of the threshold is ambiguous. Tavoni et al. (2011) explore inequality and threshold uncertainty and find that inequality is particularly troublesome to coordinated outcomes, and communication is important to successful coordination. The literature on ambient-based mechanisms with group fines also shows that the coordination failure occurs (Spraggon, 2002), though it can be improved upon with 
communication or better information about other players (Vossler et al., 2006; Poe et al., 2004; Spraggon, 2013).

In contrast to most of these previous studies, we test the influence of different forms of communication in a coordination game with varying levels of threshold uncertainty. Our game does not revert to a prisoner's dilemma as in Barrett and Dannenberg (2012). We test the joint and individual effects of communication and threshold uncertainty on coordination failures and equilibrium selection while most previous studies focus on either communication or threshold uncertainty. For example, Wit and Wilke (1998) and Vossler et al. (2006) do not vary the levels of threshold uncertainty and only evaluates one type of communication. Our design allows us to identify whether the presence or level (through increased variance) of threshold uncertainty is important to coordination, and how communication -both intra-generational and intergenerational- may resolve coordination failure.

To understand the interaction between environmental uncertainty and communication, we use a threshold public bad game and two communication treatments: cheap talk between group members (unrestricted) and anonymous written communication from one generation of subjects to another (restricted). This work is one of the first experiment-based studies to apply social learning, through one-way written communication, to a coordination game (ambient-based mechanism or threshold public goods). We define social learning as learning from other subjects, which can include learning about the game or the strategy space ${ }^{5}$. In practice, this type of communication is important to environmental problems, since it involves information from outside experienced parties (e.g., such as farmers, fishermean, or experts)-that relay information about the coordination game but are not parties to the game itself. Cheap talk occurs when group members are given time for open dialogue during a part of the experiment that is non-binding and free-form. The written communication is given by experienced (first generation) subjects to future inexperienced (second generation) subjects, and portions of the future subjects' earnings are provided to the firstgeneration participants as incentives to leave "good"well-thought-out advice. Written communication allows for learning across generations of subjects; similar intergenerational advice experiments have been used in studies involving linear public good games (Chaudhuri et al., 2006, Schotter and Sopher, 2003). Social learning, as defined, can also occur during the cheap talk sessions, though our written communication treatment is a cleaner test of social learning than cheap

\footnotetext{
${ }^{5}$ Sometimes social learning can refer to learning about others rather than from others.
} 
talk since it separates social learning from other coordination actions with other group members in the same game. Intergenerational written communication allows individuals who experience the coordination game under uncertainty to advise individuals who have not yet experienced it. It can improve participants' understanding of the coordination game in the absence of an ability to negotiate with others in the group and make promises to group members, aspects of communication that can be important in establishing and maintaining the socially preferred equilibrium. Cheap talk is less restrictive than intergenerational communication because cheap talk can involve non-binding commitments. Another difference is that cheap talk involves two-way communication while anonymous written communication goes only one-way.

We find that most groups that have an opportunity to communicate can coordinate the payoff-dominant equilibrium and that cheap talk is more effective than intergenerational communication in promoting the desired equilibrium. Also, groups seem able to overcome threshold uncertainty with communication after repeated cheap talk sessions. The strategies used in the two communication treatments are strikingly similar-groups take the lowest possible threshold and propose to split the cost of ensuring that production never exceeds that minimum threshold, a symmetrically safe strategy. The written and verbal communication show that groups rarely agreed to other approaches. Individuals in our experiment often deviate from their stated agreement to shoulder an equal share of the burden of reducing production during the experiment. However, these groups collectively maintain an asymmetric Nash equilibrium. Thus, while group objectives are negotiated through communication, the asymmetric equilibrium is negotiated through actions.

\section{Model}

Our model is similar to the group fine mechanism for ambient pollution (Spraggon, 2002; Vossler et al. 2006, Suter et al. 2010; Spraggon, 2013) in which individual actions cannot be observed. Individuals are exposed to two sources of uncertainty: strategic uncertainty about other group members' actions and threshold uncertainty about the threshold target that determines whether damages are incurred. We use this model to induce a non-linear threshold public bad game where the payoff function is non-linear in production decisions. In the model, $I$ symmetric subjects make up a group in the game, and each member of the group has the same payoff function, which is defined as 


$$
\pi_{i}\left(x_{i}\right)=f\left(x_{i}\right)-\delta \times \operatorname{Prob}\left(X_{-i}+x_{i}+\varepsilon>\bar{X}\right) .
$$

We define $f\left(x_{i}\right)$ as continuous in $x_{i}$ and as a concave function with diminishing marginal returns in $x_{i}$ where $f^{\prime}\left(x_{i}\right)>0$ and $f^{\prime \prime}\left(x_{i}\right)<0$. The level of production for individual $i$ is $x_{i}$, and $X_{-i}$ is the sum of other group members' chosen level of $x_{i}, X_{-i}=\sum_{j \neq i}^{J} x_{j} . \bar{X}$ is the threshold target for the group's production, and if the group's production exceeds that value, each group member incurs damage of size $\delta .{ }^{6}$ The error term, $\varepsilon$, is the source of threshold uncertainty about the target level to be met to avoid damages. Similar to public good games, individuals in the groups can invest in the public good to avoid damage by producing less, but will benefit only if the group coordinates to produce less than the threshold collectively. The cost of the investment is foregone income from production.

Uncertainty enters subjects' decisions through the perceived behavior of group members and the distributional assumptions from which uncertainty is drawn. We assume that $X_{-i}$ and $\varepsilon$ are random variables that represent strategic and environmental uncertainty which have a probability density function of $g\left(X_{-i}\right)$ and $s(\varepsilon)$, respectively. Thus, the beliefs about what others will produce and the realization of the threshold enter into expectations. We define an individual group member as "pivotal" if

$$
E\left(X_{-i}+\varepsilon\right) \leq \bar{X}
$$

Thus, if an individual expects that production by the other group members and the error term are less than or equal to the threshold, the individual is considered to be pivotal to the group's incurring damages.

This framework extends the model of threshold uncertainty in a discrete public good game put forth by McBride (2006). In our model, the contributions are a continuous function of $x_{i}$ rather than a binary choice set. When individuals believe that they are pivotal, the variance of the convolution of the random variables determines whether the probability of exceeding the threshold multiplied by the cost incurred as damages is greater than the marginal benefit of an increase in production. The definition of the pivotal individual depends on the sum of the means of the random variables relative to the threshold at which damages occur. When individuals believe that they are not pivotal, it is optimal for them individually to maximize production, and, consequently, coordination will likely fail. This model specification is important as it explicitly considers forms

${ }^{6}$ Since the subjects are abating production to avoid damage, this game can be viewed as a public "bad" game. 
of uncertainty in the coordination game. The means and variances in the random variables in our model can clarify how strategic and environmental uncertainty affect the group's choice of an equilibrium, which is based on individual members' expectations and uncertainty. We use uniform distributions of the random variables in the following propositions and expand on a combination of other distributions in Appendix B. ${ }^{7} \mathrm{~T} \oplus \mathrm{We}$ evaluate the implications of multiple sources of uncertainty put forwardusing two propositions that demonstrate the difference between the marginal probability of increasing production under one and two sources of uncertainty.

Proposition 1: When there is only one source of uncertainty, an increase in the variance of the random variable decreases the marginal probability that a pivotal individual will exceed the threshold.

Proof: Given that $g(y)$ is a random variable that is uniformly distributed, $y=U[-a, a]$. Assume that the threshold is contained in the variance of the random variable, $-a<\bar{X}<a$. Therefore, $\frac{\partial \operatorname{Prob}\left(X>\bar{X} \mid\left(E\left(X_{-i}+\varepsilon\right) \leq \bar{X}\right)\right)}{\partial x_{i}}=\frac{1}{2 a}$. As $a$ increases, the marginal probability of incurring damage decreases.

Proposition 2: When two sources of uncertainty are present and centered over the same mean (each represented by a random variable), the random variable with the largest variance will determine the magnitude of the marginal increase in probability when assuming that the random variables are uniformly distributed.

Proof: The convolution of two independent random variables, $g=U[-a, a]$ and $s=U[-b, b]$, has a probability density function equal to $g \otimes s=S=g+s$ where $b<a$ and $0<S<a-b$. Assume that the threshold is contained in the summation of the two probability distributions and that $S=\bar{X}$. The probability density is $p(S)=\int_{S-b}^{S+b} \frac{1}{2 a} \frac{1}{2 b} d x=\frac{1}{2 a}$. Therefore, $\frac{\partial \operatorname{Prob}\left(X+\varepsilon>\bar{X} \mid\left(E\left(X_{-i}+\varepsilon\right) \leq \bar{X}\right)\right)}{\partial x_{i}}=\frac{1}{2 a}$. ${ }^{7}$ We explore uniform distributions here because we used a uniform distribution for environmental uncertainty in the
experiment. 
In proposition 2, we refer to the random variable that has the larger variance as the source of uncertainty that dominates the marginal probability that a group will contribute to the public good and as the critical source of uncertainty for the pivotal individual. This proposition also makes an important assumption, that the two distributions are centered over each other. If the means of the distributions are separated by a large enough margin, we do not need to take the convolution of them to determine the probability density function. ${ }^{8}$ We also show in Appendix B the convolution of two normal distributions and of one uniform and one normal probability density function centered on the threshold target. When two normal densities are assumed, neither of the variances strictly dominates the marginal probability of exceeding the threshold because a reduction in either variance can affect the equilibrium selected. Thus, depending on the nature of the distribution taken by the random variables, one of the sources of uncertainty may be inconsequential to individuals' behavior if the individuals believe they are pivotal. We assume a uniform distribution for the random variable that represents threshold uncertainty in the experiment. The distribution of strategic uncertainty is unknown.

Multiple equilibria exist in this model. The symmetric Pareto-ranked equilibria are straightforward. Individuals who believe that the other group members will choose levels of production that fall below the threshold have an incentive to restrict their production, so the group does not exceed the threshold and avoids incurring damages, conditional on the level of uncertainty. In the symmetric case, the actions of all of the individuals in the group are the same and equilibrium is reached when $E\left(\sum x_{i}+\varepsilon\right)<\bar{X}$. In the absence of uncertainty, the optimal response for each individual $i$ is to produce $x_{i}^{*}=\bar{X} / I$ and to meet the threshold target. We refer to this as the symmetric payoff-dominant (PDnt) equilibrium. When uncertainty is present, the pivotal individual evaluates the conditions given in equations (3) and (4):

$$
\frac{\partial f\left(x_{i}\right)}{\partial x_{i}} \geq \delta\left(\frac{\partial \operatorname{Prob}\left(X+\varepsilon>\bar{X} \mid\left(E\left(X_{-i}+\varepsilon\right) \leq \bar{X}\right)\right)}{\partial x_{i}}\right) \text { then } x_{i}^{*}=x_{i}^{\text {Max }}
$$

$$
\frac{\partial f\left(x_{i}\right)}{\partial x_{i}}<\delta\left(\frac{\partial \operatorname{Prob}\left(X+\varepsilon>\bar{X} \mid\left(E\left(X_{-i}+\varepsilon\right) \leq \bar{X}\right)\right)}{\partial x_{i}}\right) \text { then } x_{i}^{*}=\hat{X} / I \text {. }
$$

\footnotetext{
${ }^{8}$ Experimentally this would occur when the expected value of your groups' production is higher than the range of possible thresholds, which makes the only rational option (for subjects) to maximize their production and expect that the threshold will be broken.
} 
2 These conditions are for a risk-neutral individual, and the expected value of $\varepsilon$ is equal to zero, though it can have a positive variance. In the experiment, the damage term is held constant and is large enough to retain the properties of a coordination game throughout the treatments. The condition for multiple equilibria to exist depends on the probability distribution of $\bar{X}$ and the size of damages jointly as shown in equation (3).

When the combination of strategic and environmental uncertainty is small enough and the damage incurred is large enough, the game maintains multiple equilibria as a coordination game and the symmetric Nash equilibrium is given in equation (4), where $\hat{X}$ is the group target that avoids damages, and $I$ is the number of players in the group. This game reverts to a prisoner's dilemma type game if the size of the damages, $\delta$, is small enough (as is the case in Barrett and Dannenberg (2012)) or the marginal probability of avoiding the damage is small as dictated by the condition given in equation (3), which arises when there are large variances in the random variables that drive uncertainty. ${ }^{9}$

It is still possible to free-ride on others in this game and thereby generate a set of nonsymmetric equilibria, which is not possible in some coordination games due to the binary nature of the choice set or the structure of the game. In our model, $X_{-i}=\sum_{i \neq j} x_{i}$ is the sum of the production levels chosen by individuals in the group other than person $i$. The asymmetric equilibria are possible if the other group members choose levels of production that exceed the symmetrical PDnt equilibrium with actions $x_{j}^{A}$ but fall below the threshold $X_{-i}^{A}<\bar{X}$. An equilibrium is asymmetric when the pivotal individual chooses, $x_{i}^{A}$, the difference between $\bar{X}$ and $X_{-i}^{A}$ for production to stay under the threshold, which is the individual's optimal response. These actions encapsulate a continuum of equilibria that hold the group's production equal to the threshold. These equilibria under environmental certainty result in group production equal to the threshold, $\sum x_{i}^{A}=\bar{X}$. We refer to these as the asymmetric PDnt equilibrium.

Regardless of whether uncertainty is present, an individual who believes that the other group members will exceed the threshold and for whom $\operatorname{Prob}\left(X_{-i}+x_{i}+\varepsilon>\bar{X}\right)=1$ is not a

\footnotetext{
${ }^{9}$ This change in the nature of the game occurs when the size of the damage incurred makes the marginal damage incurred by individual $i$ less than the marginal benefit of producing more at the threshold, therefore reducing the set of equilibria to the typical prisoner's dilemma dominant-strategy equilibrium of producing the maximum possible. The game could revert to a coordination game with repeated play as represented by strategies laid out by in the Folk Theorem (Fudenberg and Maskin, 1986).
} 
pivotal individual. The optimal action for that individual is to maximize the $f\left(x_{i}\right)$ function and accept damages as inevitable, which leads to actions $x_{i}^{\text {Max }}$ for all individuals identical to the condition in equation (3). We refer to this as the payoff-dominated (PDed) equilibrium.

The social preferences for these Pareto-ranked equilibria $\operatorname{are}^{10}$ :

\section{Symmetric payoff-dominant $>$ Asymmetric payoff-dominant $>$ Payoff-dominated}

The social preferences provide an ordering of the different possible equilibria from the social planner's perspective. Ignoring distributional concerns, this provides an ordered objective of desired equilibria for the group.

\subsection{Risk Aversion}

The choice of one equilibrium can be affected by the degree of risk aversion of the subjects and their expectations of the probabilities of others contributing to the public good. Selection of some of the PDnt equilibria comes with a "gamble"; the group may choose to exceed a particular threshold where the probability of incurring damage is greater than zero. Even when strategic uncertainty is eliminated there remains a risk of incurring damage from environmental uncertainty. For instance, the expected symmetric PDnt play is given by

$$
E U\left(x_{i}^{*}\right)=f\left(x_{i}^{*}\right)-\delta \times \operatorname{Prob}\left(X_{-i}+x_{i}^{*}+\varepsilon>\bar{X}\right)
$$

Given a subjective probability of that sum of random variables of the group's production, $\sum x_{i}$, we can calculate the likelihood of payoffs and compare that to the guaranteed minimum payment available through the PDed equilibrium. We can also compute certainty equivalence for subjects who produce more than the minimum threshold, where the minimum threshold would be the amount of production that eliminates environmental uncertainty. In the absence of strategic uncertainty, the individuals may prefer a level of production that could eliminate environmental

\footnotetext{
${ }^{10}$ This social preference ordering is true as long as the distributional losses from asymmetry are smaller than damages from exceeding the threshold. This is true for all asymmetric distributions in the parameterization in our experiment.
} 
uncertainty_-production at a symmetrical PDnt equilibrium that falls below the minimum threshold, a symmetrically safe equilibrium.

As in McBride (2006), the magnitude of the potential damages and the distribution of environmental uncertainty can influence the equilibrium preferred by risk-averse individuals since the characteristics of environmental uncertainty influence the probability of believing that the PDnt equilibrium can be achieved. A decrease in the magnitude of potential damage might eliminate the PDnt equilibrium, changing the game to a prisoner's dilemma. Under the prisoner's dilemma game, regardless of the individual's degree of risk aversion, the expected probability of the group reaching the PDed equilibrium is one according to expected utility theory. Thus, an increase in environmental uncertainty could, in turn, have the same effect by making the marginal value of reducing production by one unit less valuable $\left(\frac{\delta}{2 a}\right)$, at which point the PDed equilibrium also becomes the only Nash equilibrium available.

\subsection{Communication}

We incorporate communication in the experiment to understand how social learning and cheap talk affect coordination and achievement of the PDnt equilibrium. We can control for environmental uncertainty in the experiment, but strategic uncertainty derives from the subjects. Communication may reduce strategic uncertainty by allowing participants to gain information about the subjective probability that the group will meet some threshold target. Communication also provides opportunities for members of a group to learn about the strategies, preferences, and degree of risk aversion of other members as well as establish common information across the group.

We predict that communication will increase the marginal probability of meeting the threshold, $\operatorname{Prob}\left(X_{-i}+x_{i}^{*}+\varepsilon>\bar{X}\right)$, because it will provide greater clarity about $X_{-i}$ and the level of risk acceptable to the group and therefore will increase the probability of maintaining coordination. $^{11}$

\section{Experimental Design}

\footnotetext{
${ }^{11}$ In all cases, the environmental uncertainty can be eliminated. How groups deal with threshold uncertainty when environmental uncertainty cannot be eliminated is another interesting case.
} 
We parameterize the experiment with the following values. ${ }^{12}$

$$
\pi_{i}\left(x_{i}\right)=45-0.002\left(100-x_{i}\right)^{2}-24 \times \operatorname{Prob}\left(X_{-i}+x_{i}+\varepsilon>\bar{X}\right)
$$

3 The threshold target for all treatments is $\bar{X}+\varepsilon=150+\varepsilon$. We assume that the properties of the 4 error term are $\varepsilon \sim U[-a, a]$, which defines threshold uncertainty. The properties of the uniform distribution vary in three threshold uncertainty treatments: certainty, low uncertainty, and high uncertainty (see Table 2). We parameterize the experiment so that the uniform distribution's treatment. group, so the symmetric PDed equilibrium is $\sum x_{i}^{\operatorname{Max}}=600$. The symmetric Nash equilibrium $\left(x_{i}^{*}\right)$ in the certainty treatment results in a production of $x_{i}=25$ for each individual $i$ and group production of $\sum x_{i}=150$. The groups can avoid incurring damages in all of the treatments if their production choices are equal to or less than $\bar{X}-a$ from a uniform distribution of $\varepsilon=U[-a, a]$.

The symmetric Nash equilibria presented in Table 2 represent risk-neutral individuals. For risk-averse individuals, the solutions for the certainty and low-uncertainty treatments are the same because of the magnitude of the potential damages relative to the degree of threshold uncertainty. In the high-uncertainty treatment, the optimal level of production for the group would meet the minimum threshold and avoid the damages with certainty at $x^{*}=18.33$ given a constant relative risk-aversion utility function, $U(C)=C^{1-\gamma} /(1-\gamma)$ and $\gamma$ being greater than or equal to $0.145 . .^{13}$

In the experiment, the damages were set at $\delta=24$ for all treatments so that we retained the properties of a coordination game when subjects had risk-neutral preferences. The treatments allow us to measure how threshold uncertainty affects both coordination by subjects and the ability of different types of communication to facilitate achievement of the preferred equilibrium.

\footnotetext{
${ }^{12}$ This parameterization is motivated by prior studies of ambient pollution (Vossler et al. 2006, Suter et al. 2010) in which the quadratic function was defined to replicate diminishing marginal returns from $x$, which also cause an external cost to society through pollution. The curvature of the function captures technological constraints on pollution control and benefits to production much like other typical production functions. In a sense, this parameterization can be thought of as a public bad game since provision of the public good is accomplished by reducing production.

${ }^{13} \mathrm{We}$ collected information on risk preferences at the beginning of the experiment using a menu of lottery choices from Holt and Laury (2002). The results indicated significant risk-aversion $(\gamma=0.50$ on average), though using the risk-aversion measures in analysis of choice provided no significant insight into subject behavior.
} 


\section{Experimental Procedures}

In 2014, we conducted ten experiment sessions, each involving eighteen graduate-student participants, in a laboratory setting using Zurich Toolbox for Readymade Economic Experiments (Fischbacher, 2007). Subjects first participated in five practice rounds that did not affect their cash earnings to become familiar with the game. Data from those rounds were excluded from the analyses. The formal experiment session involved 48 rounds grouped into three parts of 16 rounds each identified as parts 1,2, and 3 in which one of the threshold uncertainty treatments was applied.

The laboratory stations were equipped with privacy screens, and no communication was allowed during the rounds. At the end of parts 1 and 2, the subjects were told they were being randomly assigned to a new, anonymous group before proceeding to the next part of the game. The order in which the uncertainty treatments were assigned to the groups was randomized, and subjects received no information about the uncertainty treatments or the number of parts in the experiment.

At the mid-point of each part (between rounds 8 and 9), subjects were given the opportunity to participate in cheap talk. Each group was taken to a separate room set up with a table, six chairs, a calculator, and a timer and were given three minutes to interact. Separate rooms were used to prevent contamination of ideas across groups. After the cheap-talk breaks, the subjects were brought back to the laboratory to complete the remaining eight rounds, and no communication was allowed during that part of the experiment.

Though the cheap-talk periods eliminated the anonymity of the group's members, the choices they made before or after the break were not shared; only their group's collective level of production was reported to the subjects through all rounds. Since each part of the experiment involved three groups of six subjects per group, some subjects likely had more than one interaction with some of the individuals during the experiment. However, the subjects were not told how many parts there would be and did not know before the first part that regrouping would occur. In addition, all the individuals' actions were anonymous. Therefore, it is unlikely in our view that the cheaptalk breaks acted in the capacity of building reputation during the experiment that would occur if contributions were public. Communication also provides opportunities for members of a group to learn about the strategies, preferences, and degree of risk aversion of other members as well as establish common information across the group. 
The intergenerational-advice treatment was implemented by assigning the first five 2 experiment sessions as the first generation. Participants in those sessions were asked, at the end of the experiment, to leave written advice for the future second generation of participants - those participating in the next five experiment sessions. ${ }^{14}$ We matched the order in which the uncertainty treatments were assigned to parts 1,2, and 3 in the first- and second- generation sessions to control for ordering effects. The first-generation subjects were also informed that they would receive a payment equal to $25 \%$ of the second-generation cohorts' earnings, and they were asked to address an envelope in which that payment would be mailed to them ${ }^{15}$. This step was taken to give firstgeneration subjects a stake in the second generation's outcomes, which incentivizes first generation subjects to give good advice. The anonymous advice, which was printed and distributed to subjects at the beginning of the second-generation sessions (after the economic game was explained), linked a subject in the first generation to a subject in the second generation. ${ }^{16}$

In each round, subjects received a chart showing the potential payouts for each level of production by the group and selected an amount between 0 and 100 to produce. The instructions noted that the individual payoffs would be determined by the group members' private production decisions and the group's collective level of production and that the group's production would determine whether damages equal to 24 experimental dollars per member would be levied because the group exceeded the threshold. The instructions presented examples of the parameters of threshold uncertainty and the point at which damages would be incurred. Cash payments were made to subjects at the end of the experiment at a rate of $\$ 1$ US dollar for 80 experimental dollars. The full instructions are provided in Appendix A.

\section{Predictions}

To make specific predictions about the subjects' behavior, we defined two metrics based on the group outcomes. The first was avoidance of damage. We defined a binary variable equal to 1 when

\footnotetext{
${ }^{14}$ Advice was recorded on the computer and the advice was free form and the content and length were at the sole discretion of the subject providing the advice. Subjects were aware that their advice was given to one future generation subject that would experience the same experiment they just experienced.

${ }^{15}$ The payment to the first generation was not subtracted out of the second generations earnings.

${ }^{16}$ In one case, the first-generation subject left a comment and question for the experimenters and no advice so the written advice provided to the second-generation subject simply said "No Advice Provided."
} 
the group avoided damage and 0 otherwise. This metric is interpreted as successful avoidance of

2 a catastrophe and therefore is a measure of group coordination. The other metric was the probability of damage being incurred as defined in equation (7).

$$
\operatorname{Prob}(\text { Damages })=\operatorname{Prob}\left(X_{-i}+x_{i}+\varepsilon>\bar{X}\right)
$$

5 This probability is informative because the symmetric PDnt equilibrium is associated with low or no probability of incurring damage while the PDed equilibrium is associated with a high probability of incurring damage (equal to 1). It is also important to state these predictions of group production are relative to $\bar{X}$ since this determines if an individual is pivotal. Increases in either strategic or environmental uncertainty can affect the likelihood of the PDnt equilibrium by reducing the marginal probability of increasing one unit of production or increasing the expectations that the individual is a pivotal individual. The change in probability as measured in equation (7) is a combination of both of these effects. We cannot separate the two effects, but attempt to identify the net effect on coordination. We test the following five predictions.

\section{Prediction 1: Cheap talk will increase the likelihood of achieving the PDnt equilibrium.}

Cheap talk has been shown to work well in improving coordination in prior experiments. We expect that cheap talk will increase the likelihood of a coordinated outcome and significantly improve welfare due to the ability of the subjects to engage in non-binding two-way communication.

Prediction 2: Intergenerational advice will increase the likelihood of reaching the PDnt equilibrium.

Intergenerational advice is a more restrictive one-way type of communication in which experienced players can impart advice to future players. It is expected to be associated with a smaller increase in coordination than two-way free-form communication. ThoughEven though we expect the transfer of strategic information about game strategy from one generation to the next to increase coordination and therefore reduce the likelihood of coordination failure.

Prediction 3: An increase in threshold uncertainty will decrease the likelihood of reaching the PDnt equilibrium after cheap talk sessions. 
As threshold uncertainty increases, so does the incentive to choose the PDed equilibrium, though the group can avoid damages completely by choosing a level of production below the minimum threshold. We test how disruptive the presence of threshold uncertainty is when strategic uncertainty can be mitigated through cheap talk. We note that with two sources of uncertainty it is possible that one source of uncertainty may dominate the other, per proposition 2. So, by potentially minimizing strategic uncertainty through communication (or holding it relatively constant), we may be able to isolate the role of threshold uncertainty on coordinated behavior.

Prediction 4: The absence of communication will decrease the likelihood of achieving the PDnt equilibrium when threshold uncertainty is high.

Given the results of prior studies (Spraggon, 2002; Vossler, 2006), we expect to observe a greater level of coordination failure when environmental uncertainty is high and there is no communication. Essentially this prediction is a combination of results of the first three predictions.

Prediction 5: Strategic uncertainty will marginally dominate environmental uncertainty for the pivotal individual.

We test the marginal dominance of the random variables (proposition 2) by varying the level of both types of uncertainty. We posit this prediction because while threshold uncertainty can be eliminated, it is likely more difficult to ensure the subjects are completely sure about others' future behavior without any additional commitment mechanisms. This proposition suggests that threshold uncertainty is irrelevant for the marginal decision made by subjects to maintain production under the threshold if subjects are not sure about others' behavior. Thus, if strategic uncertainty marginally dominates environmental uncertainty, environmental uncertainty will not be influential in coordinating actions when the level of strategic uncertainty is high. This outcome would depend on the distributional assumptions of the independent random variables, and can thus provide insight into behavioral responses to multiple sources of uncertainty.

\section{Results}

We obtain insight into subjects' responses to communication by comparing their average production choices in various rounds (see Figure 1). Cheap talk is effective since average 
production by the subjects appears to converge to the socially preferred equilibrium while they remain in a group and there is a sharp drop in average production after the cheap-talk sessions (dashed maroon lines in Figure 1). After the subjects were assigned to new groups for parts 2 and 3 (rounds 16 and 32), they initially chose to produce less and as the rounds progressed, some groups switch from the PDnt equilibria to the PDed equilibrium.

Written intergenerational advice appears to have a smaller effect that diminishes over time. This can be seen from the gap between the first and second generations' average production over rounds (Figure 1). After the first cheap-talk session, the effect is not significant. We also find that the communication effect appears to persist. The number of groups that switched to the inefficient equilibrium declined over time as they experienced additional communication sessions despite being randomly reassigned to new groups. This outcome reflects the effectiveness of repeated communication: with iterations of communication sessions groups converge to the socially preferable coordinated outcome. These results suggest that environmental uncertainty can be overcome with repeated communication and experience.

When considering the evolution of coordination over time, it appears that an individual's decisions are conditionally cooperative based on their groups' outcomes. When the group successfully avoids incurring damages, it is likely to continue to do so in subsequent rounds. In contrast, when a diversion away from the PDnt equilibrium occurs, groups tend to converge to the PDed equilibrium afterward. Table 3 presents the average transitions in the frequency of incurring damages between periods in a group. We find that a group is more likely to incur damage repeatedly when coordination breaks down, and more of the group's members choose to abandon the PDnt equilibrium.

\subsection{Cheap Talk}

We find that cheap talk is effective in inducing coordination in all of the threshold uncertainty treatments (certainty, low uncertainty, and high uncertainty; see Table 4). With non-binding cheap talk, the groups consistently and significantly increase the likelihood of coordination. We measure the effect of the cheap talk treatments on production decisions of individuals by uncertainty treatment in Table 4. We find that, under all uncertainty treatments, non-binding cheap talk is significant in reducing production closer to the Nash Equilibrium at the $1 \%$ level. These results support prediction 1. 
During the cheap-talk sessions, researchers observed the group members' communications and recorded the strategies agreed on in each group. The group strategies were generally consistent with two elements of the symmetric PDnt equilibrium: (1) always produce at or just below the minimum threshold and (2) share the burden equally. These agreements by groups constituted a symmetrically safe equilibrium. Those basic tenets of the subjects' non-binding agreements are generally consistent with the results of earlier experiments, which found that equity was a basic coordination rule adopted by groups (Van Dijk et al. 1999). It is a simple rule and is "fair" in the sense that no one is free-riding on others in the group. The frequency of this observation is evidence that such behavior may be common in practice even though other behavioral patterns are consistent with at least one Nash equilibrium. Thus, the non-binding agreements seemingly solve much of the coordination problem in this setting. Interestingly, even when damage is avoided, social inefficiencies may be present because of asymmetric Nash equilibria in which social welfare is not optimized. We revisit this observation when discussing the asymmetric Nash equilibria.

\subsection{Intergenerational Advice}

Table 5 shows the average production decisions of the first eight rounds in the experiment separated by generations of experimental subjects. We examine only the first eight rounds in part 1 because of the confounding effects of the cheap talk sessions, which appear to have a large impact on coordination and therefore make it difficult to analyze the effect of intergenerational advice. We find that the written advice results in a substantial improvement in coordination. Intergenerational advice reduces average production, but less so than non-binding cheap talk, and is statistically significant at the $10 \%$ level (Table 5). This result supports prediction 2 that intergenerational advice would lead to a greater likelihood of reaching the PDnt equilibrium. Social learning is somewhat effective on its own at improving coordination.

The 90 written notes advised similar approaches to play the coordination game. The following is one example of the given advice.

Always produce at the number of units that puts you at the minimum threshold. For example: if the threshold is 150, then produce 24 units. This puts you at a maximum of 144 units if each player produces 24 units. This means you will never be fined.

The advice is consistent with the two elements of strategy which subjects typically agreed to in the cheap-talk sessions. The similarity in strategies could be a function of the cheap-talk sessions, 
where all the first-generation subjects became exposed to the same strategy through group members suggesting these strategies. The intergenerational advice increases the probability of a coordinated equilibrium for second-generation subjects before they had a chance to talk to other group members.

\subsection{Threshold Uncertainty and Coordination}

The degree of threshold uncertainty affects the ability of the groups to coordinate but is buffered by cheap talk and experience. We find that the probability of coordination is highest in the certainty treatment. We illustrate how the degree of uncertainty affects the probability of incurring damages in Figure 2, which shows a series of quantile plots for each uncertainty treatment. The higher the level of threshold uncertainty, the greater the risk to the group of incurring damage. At the same time, it appears that complete convergence to the PDed equilibrium (i.e., Prob(Damages) $=1$ ) is roughly the same for low and high threshold uncertainty; production for about $25 \%$ of the groups was high enough that incurring damages was certain. ${ }^{17}$

As shown in Table 6, we find that the presence of threshold uncertainty affects coordination as well as the increase in the variance of threshold uncertainty, especially at the beginning of the experiment. Cheap talk reduces the negative effect of threshold uncertainty on coordination. In rounds 9-16 in Part 1, which were conducted after cheap talk rounds, production in all three treatments came close to guaranteeing a PDnt equilibrium, though threshold uncertainty caused a slight reduction in coordination. By Part 3, with and without communication, most of the groups were able to coordinate and avoid exceeding the threshold. This result rejects prediction 3: as communication was repeated, the presence of threshold uncertainty did not have a large impact on the probability of damages. Threshold uncertainty leads to greater coordination failure, especially in the early rounds when the subjects lack experience and are unable to communicate.

To analyze the effects of uncertainty on coordination further, we estimated a regression model of the probability of damage being incurred, by groups, as a function of the treatments in the experiment, demographic characteristics, and a lag on unsuccessful coordination. The model is given by

$$
\operatorname{Prob}\left(\text { Damages }_{t}\right)=\phi\left(\mathbf{X}_{t}^{\prime} \beta\right)
$$

\footnotetext{
${ }^{17}$ It is not clear whether participation in additional periods (rounds) by a group would lead to different convergence rates since the experiment involved only eight consecutive periods for each treatment.
} 
where the left-hand variable is the observed probability of a group incurring damages over time $t$ based on their decisions, $\phi(\cdot)$ is the standard normal distribution function, and $\mathbf{X}_{t}$ is a matrix of the explanatory variables over time. We estimated three Probit models, allowing the number of lags to vary since the inclusion of more lags reduces the number of observations and could eliminate important initial efforts at coordination. We identified the marginal effects of the treatments by comparing the mean predicted probabilities with and without the treatments.

We find that both of the-communication treatments reduce the probability of incurring damage (see Table 7). The estimates of the marginal effects show that cheap talk decreases the probability of damage by $26 \%$, which is statistically significant, and that intergenerational advice decreases the probability of damage by $6 \%$ (see Table 8 ), which is weakly significant. The effects of threshold uncertainty on the probability of damage are positive and statistically significant.

Figure 3 shows the differences in the marginal effects of cheap talk with and without threshold uncertainty. As expected, cheap talk is effective at reducing the probability of damages with and without threshold uncertainty. We can also see the slightly higher probability of damages with threshold uncertainty as the effect of experience is weaker in the first parts of the experiment. Early in the experiment, both the lack of communication and the presence of threshold uncertainty are important to coordination failure.

Additional threshold uncertainty causes a decrease in the likelihood of coordination, but only in the beginning of the experiment as shown in Table 6. The probability of damage increases $29 \%$ under low threshold uncertainty and $44 \%$ under high threshold relative to the baseline of threshold certainty (Table 8). This suggests that both strategic and environmental uncertainty are important, partially rejecting prediction 5 . With little experience in the game both sources of uncertainty appear to be important, but with more experience and repeated communication the effect of threshold uncertainty becomes insignificant. In Appendix B, we show that, when strategic uncertainty is normally distributed and centered at the threshold, environmental uncertainty should be critical for the pivotal individual but not strategic uncertainty. Another reason we might observe an effect on behavior of both forms of uncertainty is that resolving strategic uncertainty may involve a reduction in the expected mean of the group production, not just a reduction in variance, requiring the mean of group production before communication to be outside of the range of the threshold defined by environmental uncertainty. This finding highlights the importance of both forms of uncertainty on the marginal behavior of subjects without communication. The coefficient 
estimates on the dummy variables for Parts 2 and 3 in Table 7 reflect the increases in coordination from experience and repeated communication, which are economically and statistically significant. Even after the subjects were randomly assigned to new groups, the groups tended to deviate less from the PDnt equilibria, and this pattern was observed before the subjects engaged in cheap talk with their new group members. As more subjects were exposed to similar strategies, they were more likely to coordinate the group's behavior and less likely to deviate.

\subsection{Asymmetric Nash Equilibrium}

An interesting finding of this study is that more complicated behavior occurs in the continuous choice public goods game than the discrete choice public goods game with thresholds. Figure 4 demonstrates the prevalence of asymmetric equilibria, which is easiest to comprehend in the certainty treatment. Under the threshold-certainty treatment, the two symmetric equilibria require subjects to produce either 25 or 100 units. In the figure, we present the groups that produced up to the threshold of 150, so all of the asymmetric equilibria are centered on 25 . There are significant deviations by individuals in both directions, which are necessary to maintain coordination and avoid damages but also impair social welfare because the marginal incentives of all of the players are identical. The groups in the certainty treatment avoided damage in the rounds preceding cheap talk 143 times, and the standard deviation of production of the individuals in a group was greater than 3 for 83 of those times, indicating that a significant number of the group outcomes were asymmetric equilibria. It is also evident in the certainty treatment that the absence of communication leads individuals to choose an asymmetric equilibrium more often than the symmetric equilibrium. After the cheap talk, the groups conform toward distributing the burden equally, reducing the degree of variance among players and improving social welfare. The asymmetric equilibrium is also chosen in the uncertainty treatments. Additional uncertainty regarding the threshold makes welfare-impairing behavior more attractive because there is a smaller probability of incurring damage under threshold uncertainty for each marginal increase in production.

\section{Discussion}

This experiment-based study of the effects of communication and threshold uncertainty provides four important insights. First, cheap talk communication allows most groups to overcome 
coordination problems even under threshold uncertainty. Similar to Wit and Wilke (1998), who find that environmental uncertainty only matters when high social uncertainty exists, we find that environmental uncertainty is resolved after multiple rounds of communication that can reduce social uncertainty. Coordination primarily fails when communication is restricted or absent, and the failures are more severe when threshold uncertainty is also present. Second, the effects of cheap talk spill over to future rounds even after subjects are randomly reassigned to new groups during the experiment. As experience is gained through cheap talk, the groups more reliably achieve the payoff-dominant equilibrium because the subjects adopt similar strategies learned from other group members through communication. Third, cheap-talk communication is more effective than intergenerational advice. Social learning through intergenerational advice induces a higher probability of coordination, but its effect is limited. Resolving the uncertainty through two-way communication is more effective in achieving a payoff-dominant equilibrium because it is less restrictive and does not require symmetry breaking (in this experiment). We believe that cheap talk is more effective than written advice primarily because with cheap talk group members can all have access to the same information and communication is observable so that individuals can establish common knowledge, rules, and strategies with their group. Commonality and observability are lacking from written advice, and therefore, there is likely greater uncertainty of all group member'-s' future behavior. Consequently, it may be critical that communication is $\underline{\text { shared }}$

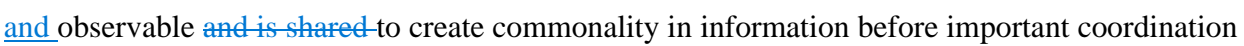
problems with threshold uncertainty can be overcome. Lastly, in the context of Bochet et al. (2017), our findings suggest that through communication subjects will trade the dangerous equilibrium for a cautious equilibrium, which is at the minimum of the threshold.

While threshold uncertainty makes the selection of the socially preferred equilibrium less likely, repeated social interactions can have a strong mitigating effect, leading many groups to achieve better outcomes. These results can be instructive for efforts to overcome important public good and coordination problems (e.g., flood management, non-point source pollution abatement, environmental tipping points.) Policies can be designed that involve repeated interactions and sharing of information through two-way verbal exchanges or making communication observable to create commonalities in information among stakeholders. Furthermore, communities that have experience with such problems can be leveraged to increase social learning in inexperienced communities and by maintaining repeated interactions to help solve coordination problems. The
Commented [EU1]: This might have been added in response to a referee comment, but I find it difficult to comprehend without defining what's 'dangerous vs cautious' equilibrium is. (apparently I haven't read Bochet et al.). Would we upset the editor if we take this sentence out? 
application of these findings is most appropriate to environmental moral hazards: when an individual's actions are hidden or costly to monitor and coordination between individuals is required to reach better group outcomes. This applies to non-point source pollution, which greatly impairs waterways, lakes, ponds, and bays throughout the world. Landowners across a watershed affect the aggregate nutrient loads downstream but attributing individual contributions of nutrient load is difficult and very costly. In the international realm, countries may also require similar communication institutions when self-reporting is relied upon to enforce an environmental objective with a shared resource, like water pollution. Self-reporting can create a moral hazard when pollution and abatement effort areis difficult to monitor across waterways shared by nations. Therefore, countries must coordinate on goals about the levels of individual and group abatement and policies to reach those goals. Lastly, lessons from this research could be applied to environmental tipping points. If private actions that deteriorate a natural resource are costly to monitor, then repeated communication and observable communication is likely paramount to maintaining the resource sustainably and avoid a collapse. It is likely not enough to document $\underline{\text { instanceseases of successful coordination as ease-studiescase studies }}$ or use expert advice to effect social learning by landowners or country representatives. Developing two-way verbal communication institutions will likely see much greater improvements to coordination failure. Our suggestion to focus on two-way communication to resolve threshold uncertainty should not be applied if symmetry breaking is required for the socially optimal solution in a coordination game setting.

Nearly all of the communications between members in our experiment explicitly discussed apportioning equal shares of the burden to avoid damage. Though the groups consistently agreed in non-binding communications to share the burdens equally, there was significant evidence of an asymmetric distribution of the burden in practice. The sustainability of the asymmetric equilibria is established through play rather than explicitly through communication with group members.

Our results show the potential effectiveness of standardized language and unstructured communication in solving some kinds of public good problems with Pareto-ranked equilibria. Our work provides empirical evidence supporting Ostrom's view that social coordination problems can be overcome by developing institutions and/or using existing institutions - by viewing language as an institution (Ostrom and Walker, 1991). Written and oral communications establish a set of behaviors mutually agreed uponen by a society of people to reduce the transaction costs associated 
1 with transmission of information and may be useful in resolving strategic and environmental 2 uncertainty to avoid coordination failures. 


\section{References}

Barbieri, S., \& Malueg, D. A. (2010). Threshold uncertainty in the private-information subscription game. Journal of Public Economics, 94(11), 848-861.

Barrett, S., \& Dannenberg, A. (2012). Climate negotiations under scientific uncertainty. Proceedings of the National Academy of Sciences, 109(43), 17372-17376.

Barrett, S. and Dannenberg, A. (2014). On the Sensitivity of Collective Action to Uncertainty about Climate Tipping Points. Nature Climate Change, 4, 36-39.

Blume, A., \& Ortmann, A. (2007). The effects of costless pre-play communication: Experimental evidence from games with Pareto-ranked equilibria. Journal of Economic theory, 132(1), 274-290.

Bochet, O., Laurent-Lucchetti, J., Leroux, J., \& Sinclair-Desgagne, B. (2017). Collective RiskTaking in the Commons. Working Paper.

Budescu, D. V., Rapoport, A. \& Suleiman, R. (1990). Resource Dilemmas with Environmental Uncertainty and Asymmetric Players. European Journal of Social Psychology, 20, 475487.

Budescu, D. V., Rapoport, A. \& Suleiman, R. (1995a). Common Pool Resource Dilemmas under Uncertainty: Qualitative Tests of Equilibrium Solutions. Games and Economic Behavior, $10,171-201$.

Budescu, D. V., Suleiman, R. \& Rapoport, A. (1995b). Positional Order and Group Size Effects in Resource Dilemmas with Uncertain Resources. Organizational Behavior and Human Decision Processes, 61, 225-238.

Cason, T. N., Roman M. S., and Jingjing Z. (2012). Communication and efficiency in competitive coordination games. Games and Economic Behavior 76.1: 26-43.

Charness, G., \& Grosskopf, B. (2004). What makes cheap talk effective? Experimental evidence. Economics Letters, 83(3), 383-389.

Chaudhuri, A., Graziano, S., \& Maitra, P. (2006). Social learning and norms in a public goods experiment with inter-generational advice. The Review of Economic Studies, 73(2), 357380 .

Cooper, R., DeJong, D. V., Forsythe, R., \& Ross, T. W. (1992). Communication in coordination games. The Quarterly Journal of Economics, 739-771.

Crawford, V. (1998). A Survey of Experiments on Communication via Cheap Talk. Journal of Economic Theory, 78, 286-298. 
Croson, R. T. A. \& Marks, M. B. (2000). Step Returns in Threshold Public Goods: A Meta- and Experimental Analysis. Experimental Economics, 2, 239-259.

Dannenberg, A., Löschel, A., Paolacci, G., Reif, C., \& Tavoni, A. (2014). On the provision of public goods with probabilistic and ambiguous thresholds. Environmental and Resource Economics, 1-19.

Devetag, G., \& Ortmann, A. (2007). When and why? A critical survey on coordination failure in the laboratory. Experimental Economics, 10(3), 331-344.

Duffy, J., \& Feltovich, N. (2006). Words, deeds, and lies: strategic behavior in games with multiple signals. The Review of Economic Studies, 669-688.

Ellingsen, T., \& Östling, R. (2010). When does communication improve coordination? The American Economic Review, 100(4), 1695-1724.

Fischbacher, U. (2007). z-Tree: Zurich Toolbox for Ready-Made Economic Experiments. Experimental Economics, 10, 171-178.

Fudenberg, D., \& Maskin, E. (1986). The folk theorem in repeated games with discounting or with incomplete information. Econometrica, 54(3), 533-554.

Gustafsson, M., Biel, A. \& Gärling, T. (1999a). Overharvesting of resources of unknown size. Acta Psychol. (Amst.) 103, 47-64 (1999a).

Gustafsson, M., Biel, A. \& Gärling, T. (1999b). Outcome-Desirability in Resource Management Problems. Thinking \& Reasoning, 5, 327-337.

Gustafsson, M., Biel, A. \& Gärling, T. (2000). Egoism Bias in Social Dilemmas with Resource Uncertainty. Group Processes \& Intergroup Relations, 3, 351-365.

Hastenrath, Stefan, and Phillip D. Kruss. (1992). The Dramatic Retreat of Mount Kenya's

Glaciers between 1963 and 1987: Greenhouse Forcing. Annals of Glaciology ,16, 127 33.

Heitzig, J., Lessmann, K., \& Zou, Y. (2011). Self-enforcing strategies to deter free-riding in the climate change mitigation game and other repeated public good games. Proceedings of the National Academy of Sciences, 108(38), 15739-15744.

Holt, C. A., \& Laury, S. K. (2002). Risk aversion and incentive effects. American economic review, 92(5), 1644-1655.

Kriegler, Elmar, Jim W. Hall, Hermann Held, Richard Dawson, and Hans Joachim Schellnhuber. 
(2009). Imprecise Probability Assessment of Tipping Points in the Climate System."Proceedings of the National Academy of Sciences 106 (13), 5041-46.

Lenton, T. M. (2013). Environmental tipping points. Annual Review of Environment and Resources, 38, 1-29.

Levati, M. V., Sutter, M., \& Van der Heijden, E. (2007). Leading by example in a public goods experiment with heterogeneity and incomplete information. Journal of Conflict Resolution, 51(5), 793-818.

Levati, M. V., Morone, A., \& Fiore, A. (2009). Voluntary contributions with imperfect information: An experimental study. Public Choice, 138(1-2), 199-216.

Li, Z., Anderson, C., \& Swallow, S. K. (2012). Uniform Price Mechanisms for Threshold Public Goods Provision: An Experimental Investigation (No. 14).

McBride, M. (2006). Discrete public goods under threshold uncertainty. Journal of Public Economics, 90(6), 1181-1199.

McBride, M. (2010). Threshold uncertainty in discrete public good games: an experimental study. Economics of governance, 11(1), 77-99.

Messick, D. M., Allison, S. T., \& Samuelson, C. D. (1988). Framing and communication effects on group members' responses to environmental and social uncertainty. Applied behavioral economics, 2, 677-700.

Ostrom, E., \& Walker, J. (1991). Communication in a commons: cooperation without external enforcement. Laboratory research in political economy, 287-322.

Poe, G. L., Schulze, W. D., Segerson, K., Suter, J. F., \& Vossler, C. A. (2004). Exploring the performance of ambient-based policy instruments when nonpoint source polluters can cooperate. American Journal of Agricultural Economics, 86(5), 1203-1210.

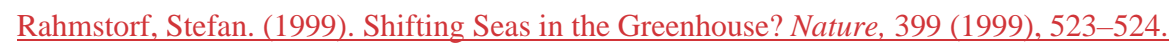

Rapoport, A., Budescu, D. V., Suleiman, R. \& Weg E. in Social dilemmas: Theoretical issues and research findings (eds. Liebrand, W. B. G., Messick, D. M. \& Wilke, H. A. M.) 4357 (Pergamon Press, Oxford 1992).

Rapoport, A., Budescu, D. V. \& Suleiman, R. (1993). Sequential Request from Randomly Distributed Resources. Journal of Mathematical Psychology, 37, 241-265.

Russell, C., DeJong, D.V., Forsythe, R., Ross, T. W. (1992), Communication in Coordination Games. Quarterly Journal of Economics, 107(2), 739-771. 
Schotter, A., \& Sopher, B. (2003). Social learning and coordination conventions in intergenerational games: An experimental study. Journal of Political Economy, 111(3), 498-529.

Segerson, K. (1988). Uncertainty and incentives for nonpoint pollution control. Journal of environmental economics and management, 15(1), 87-98.

Skyrms, B. (2001, November). The stag hunt. In Proceedings and Addresses of the American Philosophical Association (pp. 31-41). American Philosophical Association.

Spraggon, J. (2002). Exogenous targeting instruments as a solution to group moral hazards. Journal of Public Economics, 84(3), 427-456.

Spraggon, J. M. (2013). The impact of information and cost heterogeneity on firm behaviour under an ambient tax/subsidy instrument. Journal of Environmental Management, 122, 137-143.

Suleiman, R., Budescu, D. V. \& Rapoport, A. (2001). Provision of Step-Level Public Goods with Uncertain Provision Threshold and Continuous Contribution. Group Decision and Negotiation, 10, 253-274.

Suleiman, R., Rapoport, A. \& Budescu, D. V. (1996). Fixed Position and Property Rights in Sequential Resource Dilemmas under Uncertainty. Acta Psychol. (Amst.),93, 229-245.

Suter, J. F., Segerson, K., Vossler, C. A., \& Poe, G. L. (2010). Voluntary-threat approaches to reduce ambient water pollution. American Journal of Agricultural Economics, 92(4), 1195-1213.

Tavoni, A., Dannenberg, A., Kallis, G., \& Löschel, A. (2011). Inequality, communication, and the avoidance of disastrous climate change in a public goods game. Proceedings of the National Academy of Sciences, 108(29), 11825-11829.

Van Dijk, E., Wilke, H., Wilke, M., \& Metman, L. (1999). What information do we use in social dilemmas? Environmental uncertainty and the employment of coordination rules. Journal of Experimental Social Psychology, 35(2), 109-135.

Van Huyck, J. B., Battalio, R. C., \& Beil, R. O. (1990). Tacit coordination games, strategic uncertainty, and coordination failure. The American Economic Review, 234-248.

Vossler, C. A., Poe, G. L., Schulze, W. D., \& Segerson, K. (2006). Communication and incentive mechanisms based on group performance: an experimental study of nonpoint pollution control. Economic Inquiry, 44(4), 599-613. 
1 Wit, A. \& Wilke, H. (1998). Public good provision under environmental and social uncertainty.

$2 \quad$ European Journal of Social Psychology, 28, 249-256.

3

4

5

7

8 
Tables and Figures

Figure 1: Average Production by Round

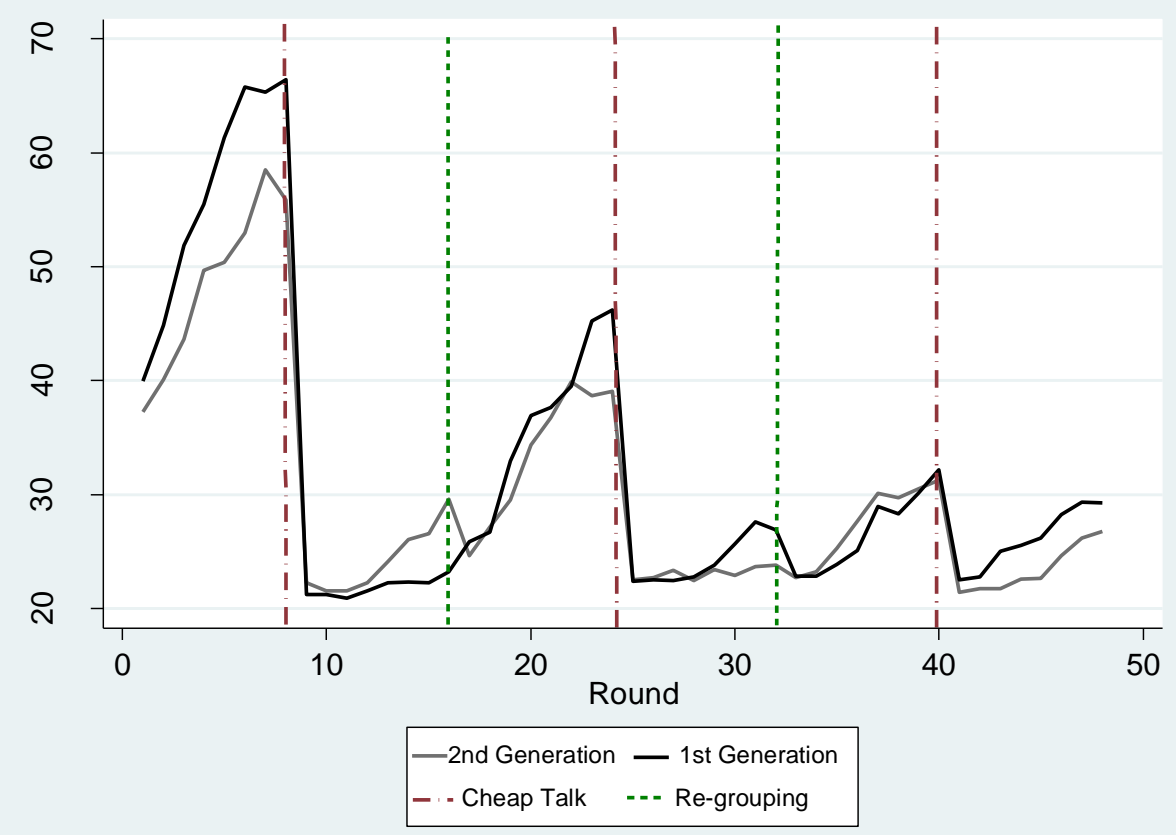

4

5 Note: This figure demonstrates average production of subjects over rounds. The maroon lines indicating 6 cheap talk show the round in which each cheap talk session occurred. The green dashed lines indicate the 7 round in which subjects were randomly regrouped into new anonymous groups during the experiment. 
Figure 2: Quantile Plot of Probability of Damages
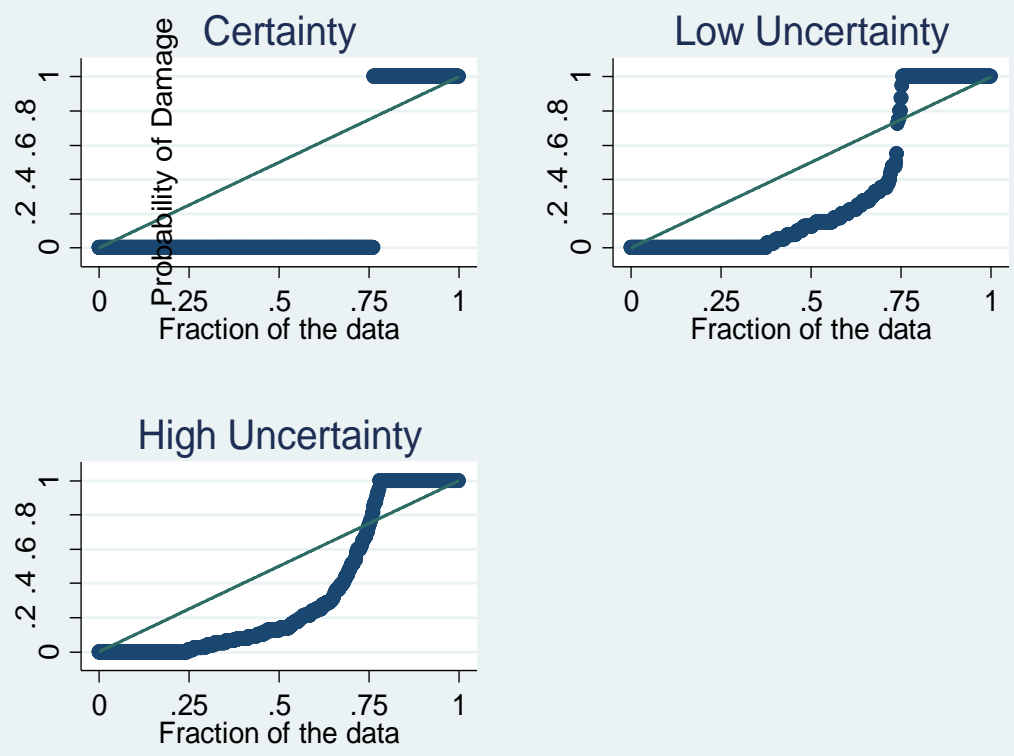

4

5 Note: This figure shows the quantile plots over uncertainty treatments. The straight lines indicate a uniform

6 cumulative distribution of the probability of damages, while the dots are data from the experiment.

7

8

9

10

11

12

13 
$4 \quad$ Figure 3: Predictive Margins of Communication and Threshold Uncertainty

\section{Fure 3. Predictive Margins of Communication and Threshold Uncertainty}
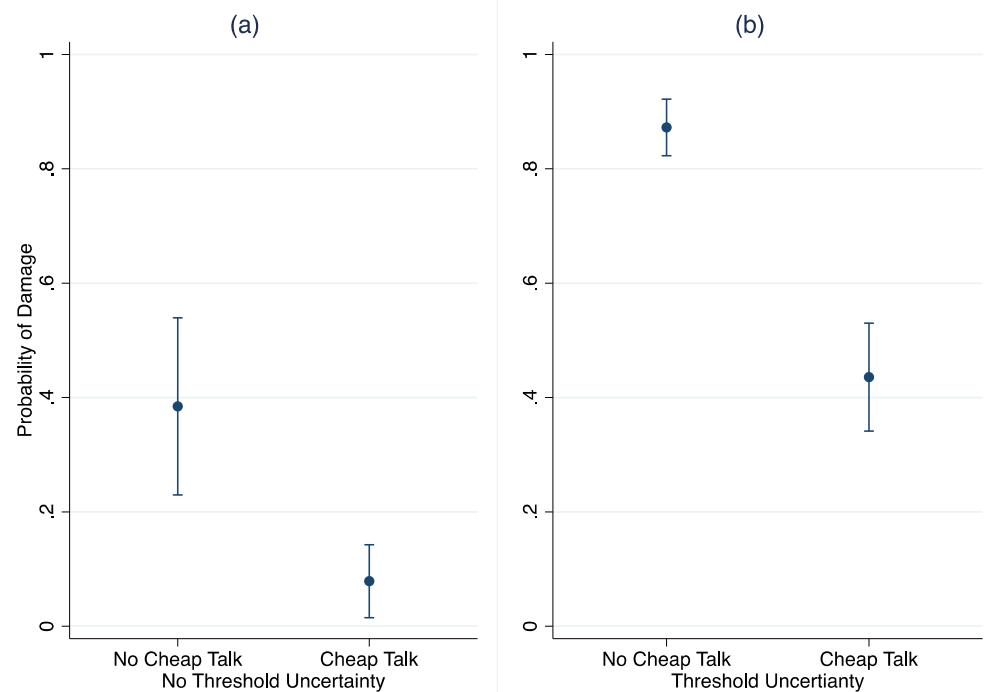

5

6 Note: This figure plots the marginal effects of cheap talk at the means of other covariates on two

7 subpopulations. Panel (a) estimates come from Model 1 from Table 7 without session fixed effects and with

8 only certainty treatments. Panel (b) estimates come from Model 1 from Table 7 without session fixed effects

9 and with only uncertainty treatments (both low and high threshold uncertainty). 95\% confidence intervals are plotted based on clustered standard errors by groups. 
$2 \quad$ Figure 4: Asymmetric Nash Equilibrium

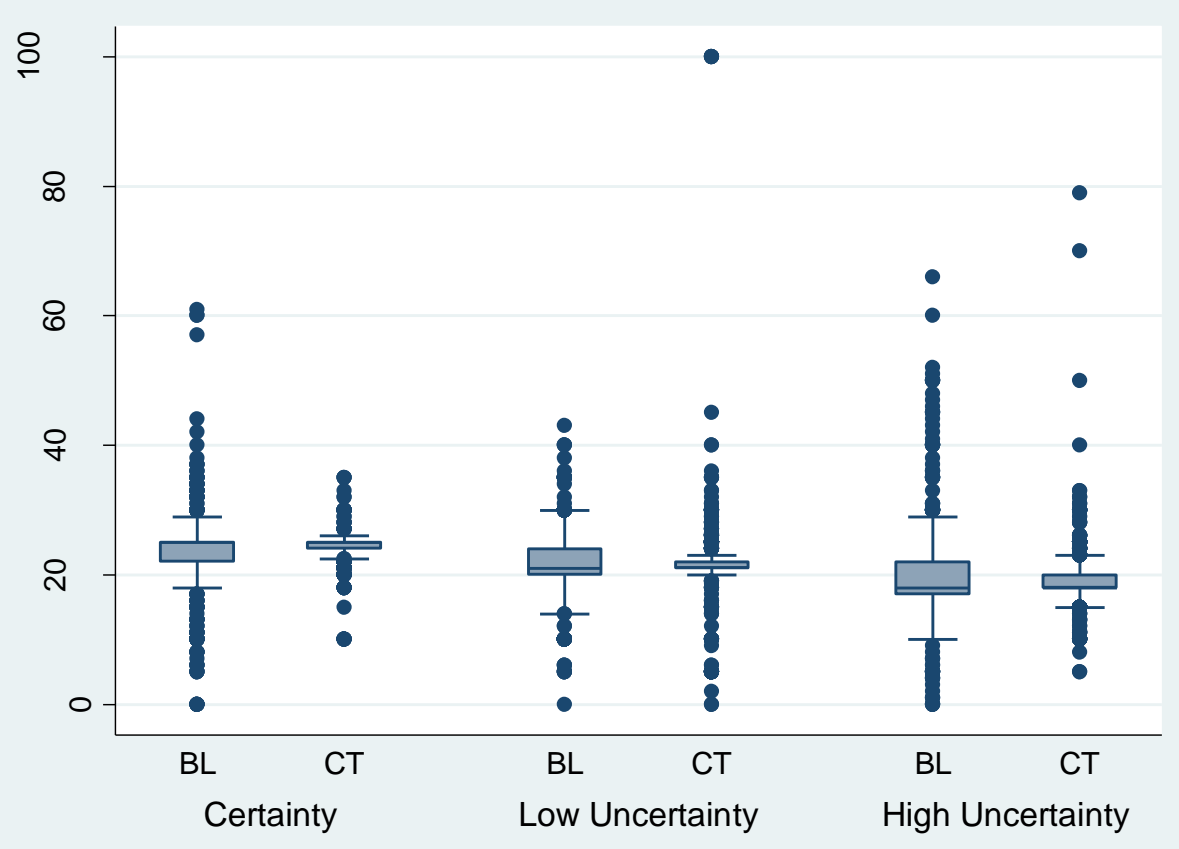

3

4 Note: This figure plots the distribution of production decisions for each uncertainty treatment. BL is the

5 baseline observations (before face-to-face communication), and CT indicates observations after a cheap 6 talk session.

7

8

9

10

11

12

13

14 
Table 1: Treatments and Session Details

\begin{tabular}{lcc}
\hline Session & Ordering of Uncertainty Treatments & Generation \\
\hline $\mathbf{1}$ & Certainty, Low Uncertainty, High Uncertainty & $1^{\text {st }}$ \\
$\mathbf{2}$ & Certainty, Low Uncertainty, High Uncertainty & $2^{\text {nd }}$ \\
$\mathbf{3}$ & High Uncertainty, Low Uncertainty, Certainty & $1^{\text {st }}$ \\
$\mathbf{4}$ & Low Uncertainty, High Uncertainty, Certainty & $1^{\text {st }}$ \\
$\mathbf{5}$ & High Uncertainty, Low Uncertainty, Certainty & $2^{\text {nd }}$ \\
$\mathbf{6}$ & Low Uncertainty, High Uncertainty, Certainty & $2^{\text {nd }}$ \\
$\mathbf{7}$ & High Uncertainty, Certainty, Low Uncertainty & $1^{\text {st }}$ \\
$\mathbf{8}$ & Low Uncertainty, Certainty, High Uncertainty & $1^{\text {st }}$ \\
$\mathbf{9}$ & High Uncertainty, Certainty, Low Uncertainty & $2^{\text {nd }}$ \\
$\mathbf{1 0}$ & Low Uncertainty, Certainty, High Uncertainty & $2^{\text {nd }}$
\end{tabular}

Note: The first-generation-session written advice given to a second-generation session follows the same ordering of uncertainty treatments (e.g., session 1 gave written advice to session 2). 
Table 2: Uncertainty Treatments

\begin{tabular}{lcc}
\hline Treatment & Properties of $\varepsilon$ & $\begin{array}{c}\text { Symmetric Nash } \\
\text { Equilibrium }\left(\boldsymbol{x}_{\boldsymbol{i}}^{*}\right)\end{array}$ \\
\hline Certainty & $\varepsilon=0$ & 25 \\
Low Threshold Uncertainty & $\varepsilon=\mathrm{U}[-20,20]$ & 21.66 \\
High Threshold Uncertainty & $\varepsilon=\mathrm{U}[-40,40]$ & 25 \\
\hline
\end{tabular}

2 
Table 3: Transition of the Frequency of Damages

\begin{tabular}{llccc}
\cline { 2 - 5 } & \multicolumn{3}{c}{ Next Period } \\
\cline { 2 - 5 } Current & & No & Damages & Total \\
Period & Damages & & \\
\cline { 2 - 5 } & No Damages & 0.606 & 0.094 & 0.70 \\
& Damages & 0.076 & 0.224 & 0.30 \\
\cline { 2 - 5 } & Total & 0.682 & 0.317 & 1.00
\end{tabular}

2 
Table 4: Production by Uncertainty Treatment and Cheap Talk

\begin{tabular}{lccc} 
& Certainty & Low Uncertainty & High Uncertainty \\
\hline (A) Without Cheap Talk & $35.79(1.512)$ & $42.32(1.790)$ & $36.61(1.830)$ \\
\hline (B) With Cheap Talk & $25.79(1.512)$ & $22.53(1.790)$ & $23.23(1.830)$ \\
\hline \multicolumn{1}{c}{ Difference $(\mathbf{A}-\mathbf{B})$} & $10.00 * * *(2.139)$ & $19.78 * * *(2.532)$ & $13.37 * * *(2.587)$
\end{tabular}

2

3

4

5

6

7

Note: Clustered standard errors by subjects are denoted in parentheses. ***, **, * denote levels of significance of $1 \%, 5 \%$, and $10 \%$, respectively and is determined by t-statistic adjusted for clustering at the subject level. The number of observations for each row and column combination is 1,440 . 
Table 5: Production by Inter-generational Advice

(1)

\begin{tabular}{cc}
\hline (A) First Generation & $56.38(2.926)$ \\
\hline (B) Second Generation & $48.54(2.926)$ \\
\hline Difference (A - B) & $7.83 *(4.138)$
\end{tabular}

Note: Clustered standard errors by subjects are denoted in parentheses. $* * *, * *, *$ denote levels of significance of $1 \%, 5 \%$, and $10 \%$, respectively and is determined by t-statistic adjusted for clustering at the subject level. The number of observations for each row $\mathrm{A}$ and $\mathrm{B}$ is 720 . The sample is limited to observations occurring before any cheap talk breaks to isolate the effect of intergenerational advice on production.

11

12

13

14

15 
Table 6: Probability of Damages by Treatment

\begin{tabular}{lcccc|ccc}
\hline \multicolumn{3}{c}{ Average Probability of Damages } & \multicolumn{3}{c}{ Differences } \\
\hline & & $(\mathbf{1})$ & $\mathbf{( 2 )}$ & $\mathbf{( 3 )}$ & $\mathbf{( 2 ) - ( 1 )}$ & $\mathbf{( 3 ) - ( 2 )}$ & $\mathbf{( 3 ) - ( 1 )}$ \\
\hline & \multirow{2}{*}{ Certainty } & Low & High & & & \\
& & & Uncertainty & Uncertainty & & & \\
After & $\mathbf{1}$ & $(0.055)$ & $(0.039)$ & $(0.066)$ & $(0.067)$ & $(0.069)$ & $(0.115)$ \\
Cheap & Part & 0.052 & 0.075 & 0.250 & 0.023 & $0.176^{*}$ & $0.198^{*}$ \\
Talk & $\mathbf{2}$ & $(0.020)$ & $(0.056)$ & $(0.079)$ & $(0.029)$ & $(0.097)$ & $(0.095)$ \\
\cline { 2 - 7 } & Part & 0.115 & 0.070 & 0.168 & -0.045 & 0.098 & 0.054 \\
& $\mathbf{3}$ & $(0.076)$ & $(0.098)$ & $(0.076)$ & $(0.120)$ & $(0.103)$ & $(0.107)$
\end{tabular}

2 Note: Clustered standard errors by groups are denoted in parentheses. $* * *, * *, *$ denote levels of

3 significance of $1 \%, 5 \%$, and $10 \%$, respectively and is determined by t-statistic adjusted for

4 clustering at the group level. Sample means are computed at the group level (the sum of subjects

5 in each six-person group). 
Table 7: Probit Regression Models

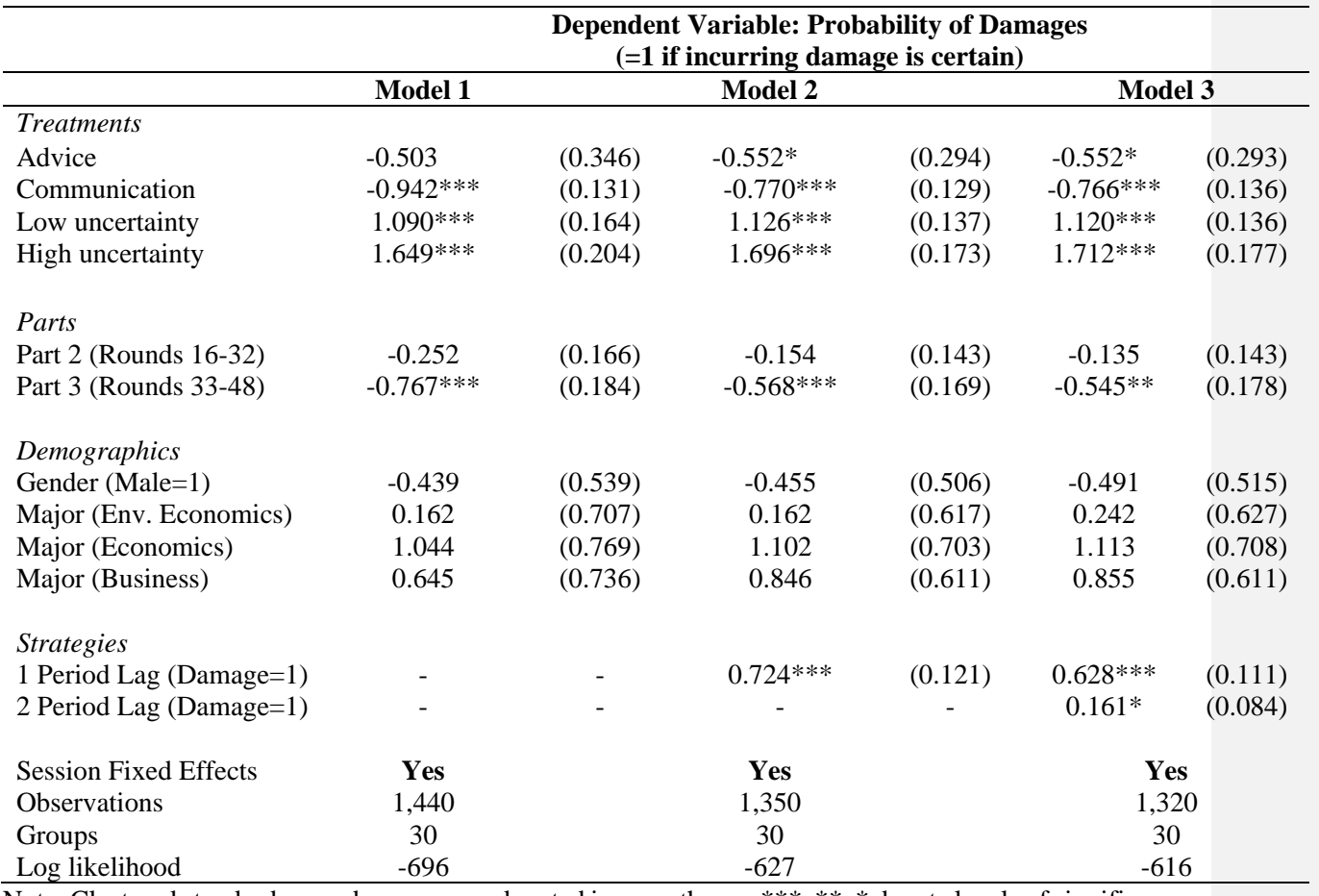

2 Note: Clustered standard errors by group are denoted in parentheses. ***,**,* denote levels of significance

3 of $1 \%, 5 \%$, and $10 \%$, respectively. Demographic variables are computed as the mean characteristics for the

4 group, while all other variables are binary variables. The omitted category for parts is part 1 . The omitted

5 category for major is other. 
Table 8: Marginal Effects from Probit Regression Model

\begin{tabular}{lc}
\hline \multicolumn{2}{c}{$\begin{array}{c}\text { Change in Probability of Incurring Damages (at Means of } \\
\text { Covariates) }\end{array}$} \\
\hline Treatments & 0.060 \\
Advice & 0.262 \\
Communication & -0.291 \\
Low uncertainty & -0.443 \\
High uncertainty & \\
\hline Note: Estimated on Model 1 without session fixed effects. Estimates are qualitatively similar \\
with lags. \\
\end{tabular}




\section{Experiment Instructions ${ }^{18}$}

\section{Introduction}

Welcome to an economic experiment about decision making at the University of Rhode Island! In the course of the experiment, you will have several opportunities to earn money. Any money earned during the experiment will be recorded as experimental dollars. At the end of the experiment, we will convert your experimental dollars into actual US dollars that will be handed to you as you leave. The more experimental dollars you earn the more actual US dollars you will receive at the end of the experiment. The conversion rate is \$1 US dollar for 80 experimental dollars. Please read these instructions carefully and do not communicate with any other participants during the experiment, unless you are instructed to do so.

\section{Production and Profit}

In today's experiment, you will be assigned to a group of six people (including yourself). You and everyone else in your group will be playing the role of one of six decision-makers. Each decisionmaker makes a product that creates revenue.

The experiment will consist of several periods, divided into different parts (we will discuss more about each part later on). In each period of the experiment, you (and others in your group) will be asked to choose a production level between 0 and 100 units. Your production generates revenue between $\$ 25$ and $\$ 45$, which increases as you produce more. A table that shows the revenue corresponding to each possible production level will be provided separately from this instruction manual. This revenue schedule will remain the same throughout the experiment.

Profit from each period is independent, meaning that decisions during a period do not affect future periods in any way. The only value that gets carried over across periods is your cumulative profit, which will be used to calculate your earnings at the end of the experiment.

\section{Group Fine}

A group fine may be incurred if the total of your group's production levels exceeds a group fine threshold. This threshold may be uncertain and its value changes within a pre-informed range after each period. Before you make the production decision in each period, you will see (1) a diagram that shows the range of values where the threshold may lie and (2) the amount of the possible group fine. The threshold range may or may not change after each part of the experiment but it will remain the same throughout a part, and so will the amount of the possible group fine.

\footnotetext{
${ }^{18}$ In a given session, the parts here were presented to subjects as Part A, Part B, and Part C in order but were shuffled to re-order the uncertainty treatment so that part A would be high uncertainty in one session and then low uncertainty in a different session.
} 
Figure 1. A group fine threshold of 153.



Random Group Fine Threshold

After everyone has made their production decisions, the actual threshold for the group fine will be determined and revealed through a random draw within the range. If a group fine is incurred, everyone in your group will be charged the same amount of fine and it will be deducted from everyone's own revenue. You and other participants will be given the information about the group's total production level. You will also receive information about whether or not a fine was incurred after the threshold is shown to the group.

\section{Communication}

You and other group members have the chance to informally communicate with each other at the beginning of certain parts of the experiment. Your group will be asked to move to a private room where you may communicate with other group members for $\mathbf{3}$ minutes. An observer will be in the same room with you while the communication takes place. There are no restrictions as to what you can discuss with other group members, although we ask you to comply with the following guidelines:

- Be polite to other participants;

- Do not threaten other participants, ask for private information, or offer financial incentives to influence the group's decisions over the course of the experiment.

After 3 minutes, you will return to the computer lab where the experiment will continue. There will be no further communication for the rest of that part of the experiment. 
1

2

3

4

5

6

7

8

9

10

11

12

13

14

15

16

17

18

19

20

21

22

23

24

25

26

\section{Experiment Schedule}

The experiment consists of several parts. The first part will have five practice periods so that you can become familiar with both the software and the experiment.

The group fine threshold could take on any value between $\mathbf{1 3 0}$ and $\mathbf{1 7 0}$ and a group fine of $\mathbf{2 4}$ will be incurred if your group's total production exceeds the threshold. As a result, in this practice part, your profit will depend ONLY on your production decision and is equal to the revenue.

\section{Example}

Suppose the threshold could be between 130 and 170, the actual threshold is 150 and your group's production level is 144 . No group fine will be deducted from each member's revenue.

Suppose the threshold could be between 130 and 170, the actual threshold is 160 and your group's production level is 220 . A group fine of $\$ 24$ will be deducted from each member's revenue.

The remaining parts of the experiment will essentially be similar to the practice part, except that each might have a different threshold range and amount of group fine (if incurred). 
This part of the experiment is similar to the practice one, except that it has the threshold and amount of group fine shown below.

\begin{tabular}{cc} 
Threshold Range & Possible Group Fine \\
\hline $130-170$ & $\$ 24$
\end{tabular}

\section{Examples}

1. Suppose the threshold could be between 130 and 170, the actual threshold is 163 and your group's production level is 144 . No group fine will be deducted from each member's revenue.

2. Suppose the threshold could be between 130 and 170, the actual threshold is 159 and your group's production level is 225 . A group fine of $\$ 24$ will be deducted from each member's revenue. 


\section{Part A}

This part of the experiment is similar to the practice one, except that it has the threshold and amount of group fine shown below.

\begin{tabular}{cc} 
Threshold Range & Possible Group Fine \\
\hline $110-190$ & $\$ 24$
\end{tabular}

\section{Examples}

1. Suppose the threshold could be between 110 and 190, the actual threshold is 173 and your group's production level is 144 . No group fine will be deducted from each member's revenue.

2. Suppose the threshold could be between 110 and 190, the actual threshold is 180 and your group's production level is 182 . A group fine of $\$ 24$ will be deducted from each member's revenue. 

9

\section{Part B}

This part of the experiment is similar to the practice one, except that it has the threshold and amount of group fine shown below.

Threshold Possible Group Fine

150 $\$ 24$

\section{Examples}

1. Suppose the threshold is $173^{19}$ and your group's production level is 144 . No group fine will be deducted from each member's revenue.

2. Suppose the threshold is 173 and your group's production level is 180 . A group fine of $\$ 24$ will be deducted from each member's revenue.

${ }^{19}$ This is a typographical error that we did not catch before running the first session, but it was explained during the experiment by reinforcing that the actual threshold was known and was equal to 150 in this part. 
Table. Revenue Schedule.

\begin{tabular}{|c|c|}
\hline $\begin{array}{c}\text { Production } \\
\text { Level }\end{array}$ & Revenue \\
\hline 0 & 25.00 \\
\hline 1 & 25.40 \\
\hline 2 & 25.79 \\
\hline 3 & 26.18 \\
\hline 4 & 26.57 \\
\hline 5 & 26.95 \\
\hline 6 & 27.33 \\
\hline 7 & 27.70 \\
\hline 8 & 28.07 \\
\hline 9 & 28.44 \\
\hline 10 & 28.80 \\
\hline 11 & 29.16 \\
\hline 12 & 29.51 \\
\hline 13 & 29.86 \\
\hline 14 & 30.21 \\
\hline 15 & 30.55 \\
\hline 16 & 30.89 \\
\hline 17 & 31.22 \\
\hline 18 & 31.55 \\
\hline 19 & 31.88 \\
\hline 20 & 32.20 \\
\hline 21 & 32.52 \\
\hline 22 & 32.83 \\
\hline 23 & 33.14 \\
\hline 24 & 33.45 \\
\hline 25 & 33.75 \\
\hline 26 & 34.05 \\
\hline 27 & 34.34 \\
\hline 28 & 34.63 \\
\hline 29 & 34.92 \\
\hline 30 & 35.20 \\
\hline 31 & 35.48 \\
\hline 32 & 35.75 \\
\hline 33 & 36.02 \\
\hline
\end{tabular}

\begin{tabular}{|c|c|}
\hline $\begin{array}{c}\text { Production } \\
\text { Level }\end{array}$ & Revenue \\
\hline 34 & 36.29 \\
\hline 35 & 36.55 \\
\hline 36 & 36.81 \\
\hline 37 & 37.06 \\
\hline 38 & 37.31 \\
\hline 39 & 37.56 \\
\hline 40 & 37.80 \\
\hline 41 & 38.04 \\
\hline 42 & 38.27 \\
\hline 43 & 38.50 \\
\hline 44 & 38.73 \\
\hline 45 & 38.95 \\
\hline 46 & 39.17 \\
\hline 47 & 39.38 \\
\hline 48 & 39.59 \\
\hline 49 & 39.80 \\
\hline 50 & 40.00 \\
\hline 51 & 40.20 \\
\hline 52 & 40.39 \\
\hline 53 & 40.58 \\
\hline 54 & 40.77 \\
\hline 55 & 40.95 \\
\hline 56 & 41.13 \\
\hline 57 & 41.30 \\
\hline 58 & 41.47 \\
\hline 59 & 41.64 \\
\hline 60 & 41.80 \\
\hline 61 & 41.96 \\
\hline 62 & 42.11 \\
\hline 63 & 42.26 \\
\hline 64 & 42.41 \\
\hline 65 & 42.55 \\
\hline 66 & 42.69 \\
\hline 67 & 42.82 \\
\hline
\end{tabular}

\begin{tabular}{|c|c|}
\hline $\begin{array}{c}\text { Production } \\
\text { Level }\end{array}$ & Revenue \\
\hline 68 & 42.95 \\
\hline 69 & 43.08 \\
\hline 70 & 43.20 \\
\hline 71 & 43.32 \\
\hline 72 & 43.43 \\
\hline 73 & 43.54 \\
\hline 74 & 43.65 \\
\hline 75 & 43.75 \\
\hline 76 & 43.85 \\
\hline 77 & 43.94 \\
\hline 78 & 44.03 \\
\hline 79 & 44.12 \\
\hline 80 & 44.20 \\
\hline 81 & 44.28 \\
\hline 82 & 44.35 \\
\hline 83 & 44.42 \\
\hline 84 & 44.49 \\
\hline 85 & 44.55 \\
\hline 86 & 44.61 \\
\hline 87 & 44.66 \\
\hline 88 & 44.71 \\
\hline 89 & 44.76 \\
\hline 90 & 44.80 \\
\hline 91 & 44.84 \\
\hline 92 & 44.87 \\
\hline 93 & 44.90 \\
\hline 94 & 44.93 \\
\hline 95 & 44.95 \\
\hline 96 & 44.97 \\
\hline 97 & 44.98 \\
\hline 98 & 44.99 \\
\hline 99 & 45.00 \\
\hline 100 & 45.00 \\
\hline
\end{tabular}




\section{Appendix B: Convolution of Other Densities for the Pivotal Individual}

Consider the two independent random variables $g$ and $s$ with $p$-dimensional normal distributions $N(a, A)$ and $N(b, B)$. We assume that the relevant threshold for a pivotal individual is at the mean of the distribution of both random variables or $a+b=\bar{X}$. The probability density function is $g \otimes s=\int g(x) s(z-x) d x$ with the new combined random variable $z$.

$$
g(z ; a+b, A+B)=\frac{1}{(2 \pi)^{p / 2}|A+B|^{1 / 2}} e^{-\frac{1}{2}(z-(a+b))^{\prime}(A+B)^{-1}(z-(a+b))}
$$

Here the joint probability density function evaluated at the threshold $\bar{X}$ is smaller than either individual probability density function. If $a+b=z$ then the probability density function simplifies to

$$
g(z ; a+b, A+B)=\frac{1}{(2 \pi)^{p / 2}|A+B|^{1 / 2}}
$$

So necessarily at this point when $A, B>0$ then

$$
\begin{aligned}
& g(z ; a+b, A+B \mid(z=a+b))<g(x ; a, A \mid(x=a)) \\
& g(z ; a+b, A+B \mid(z=a+b))<g(x ; b, B \mid(x=b))
\end{aligned}
$$

This shows that the additional uncertainty will lead to lower expected probabilities of going over the threshold for the pivotal individual.

\section{One Normal Density and One Uniform Density:}

Consider the two independent random variables $g$ and $s$ with $g=N(0, A)$ and $s=U(-b, b)$.

We assume that the relevant threshold for a pivotal individual is at the mean of the distribution of both random variables or in this case for convenience $0=\bar{X}$. The probability density function is $g \otimes s=\int g(x) s(z-x) d x$ with the new combined random variable $z$.

$$
g(z ; 0, A+B)=\frac{\Psi_{0}\left(\frac{z+b}{A}\right)-\Psi_{0}\left(\frac{z-b}{A}\right)}{2 b}
$$

Where $\Psi_{0}$ is the distribution function of the standard normal distribution 


$$
\Psi_{0}(x)=\frac{1}{\sqrt{2 \pi}} \int_{-\infty}^{x} e^{-t^{2} / 2} d t
$$

2 Examined at the threshold for the pivotal individual we can see that this is a quasi-uniform

3 distribution that depends on the ratio of $\frac{b}{A}$. Centering this distribution around zero makes the 4 comparison easier to see that within the bounds of the uniform distribution the difference 5 between the top given $\Psi_{0}(-x)=1-\Psi_{0}(x)$, the probability distribution is the uniform 6 distribution at the threshold and equal to $\frac{1}{2 b}$. In this instance the uniform distribution dominates 7 the actions of the pivotal individual.

8

\section{Appendix C: Robustness of Results}

In this section we provide additional regression results which exclude the sessions with the errors in the instructions. We believe the error was minor and the fact that subjects were informed of the threshold for each treatment before playing each round of the game, both visually and numerically, the error did not affect game play. We provide this additional regression to assuage fears that our results are not robust to the exclusion of these sessions.

We find similar results in Table 1A to the results presented in Table 7 from the main text. We additionally find that the estimates are not statistically different from each other.

17


Table 1A: Probit Regression Models

\begin{tabular}{|c|c|c|c|c|c|c|}
\hline \multirow[b]{3}{*}{ Treatments } & \multicolumn{6}{|c|}{$\begin{array}{c}\text { Dependent Variable: Probability of Damages } \\
(=1 \text { if incurring damage is certain })\end{array}$} \\
\hline & \multirow[t]{2}{*}{ Model 1} & & \multicolumn{2}{|c|}{ Model 2} & \multicolumn{2}{|c|}{ Model 3 } \\
\hline & & & & & & \\
\hline Advice & -0.518 & $(0.414)$ & -0.494 & $(0.360)$ & -0.502 & $(0.345)$ \\
\hline Communication & $-0.988 * * *$ & $(0.177)$ & $-0.814 * * *$ & $(0.171)$ & $-0.828 * * *$ & $(0.183)$ \\
\hline Low uncertainty & $1.178^{* * *}$ & $(0.225)$ & $1.169 * * *$ & $(0.193)$ & $1.183 * * *$ & $(0.185)$ \\
\hline High uncertainty & $1.780 * * *$ & $(0.272)$ & $1.771 * * *$ & $(0.235)$ & $1.813 * * *$ & $(0.235)$ \\
\hline \multicolumn{7}{|l|}{ Parts } \\
\hline Part 2 (Rounds 16-32) & -0.174 & $(0.234)$ & -0.133 & $(0.214)$ & -0.100 & $(0.219)$ \\
\hline Part 3 (Rounds 33-48) & $-0.681 * * *$ & $(0.202)$ & $-0.531 * * *$ & $(0.195)$ & $-0.490 * *$ & $(0.205)$ \\
\hline \multicolumn{7}{|l|}{ Demographics } \\
\hline Gender $($ Male $=1)$ & -0.663 & $(0.602)$ & -0.705 & $(0.558)$ & -0.700 & $(0.569)$ \\
\hline Major (Env. Economics) & 1.597 & $(1.435)$ & 1.465 & (1.183) & 1.506 & $(1.147)$ \\
\hline Major (Economics) & 0.882 & $(0.736)$ & 0.911 & $(0.667)$ & 0.932 & $(0.656)$ \\
\hline Major (Business) & 0.729 & $(0.873)$ & 0.698 & $(0.774)$ & 0.666 & $(0.774)$ \\
\hline \multicolumn{7}{|l|}{ Strategies } \\
\hline 1 Period Lag (Damage=1) & - & - & $0.676 * * *$ & $(0.176)$ & $0.532 * * *$ & $(0.149)$ \\
\hline 2 Period Lag (Damage=1) & - & - & - & - & $0.215^{*}$ & $(0.123)$ \\
\hline Session Fixed Effects & Yes & & Yes & & $\mathbf{Y}$ & \\
\hline Observations & 1,152 & & 1,080 & & 1,0 & \\
\hline Groups & 24 & & 24 & & 2 & \\
\hline Log likelihood & -519 & & -472 & & -4 & \\
\hline
\end{tabular}

5 Note: Clustered standard errors by group are denoted in parentheses. $* * *, * *, *$ denote levels of significance

6 of $1 \%, 5 \%$, and $10 \%$, respectively. Demographic variables are computed as the mean characteristics for the

7 group, while all other variables are binary variables. The omitted category for parts is part 1 . The omitted

8 category for major is other. 